\title{
Relationship and Investigation Research among the Alienation and Personality Problem Trend of Ethnic Minority Adolescents Living in Han Nationality District
}

\author{
Huang $\mathrm{Li}^{1}$, Xuan $\mathrm{Yu}^{2 *}$ and Zhijuan Deng ${ }^{3}$ \\ ${ }^{1.3}$ Business School of Yunnan University of Finance and Economics, Yunnan Kunming 650221 \\ ${ }^{2}$ Business School of Chongqing Technology And Business University, Chongqing 400067 \\ *The corresponding author
}

Keywords: Minority living in han nationality district; Adolescents; Alienation; Personality problem trend

\begin{abstract}
In the present study, 586 effective ethnic minority adolescents in Han Nationality District were surveyed by the "Adolescent Alienation Scale" and the" PAS Personality Test". The results showed that: (1) On the whole, the adolescents of minority nationalities in Han district experienced a moderate degree of alienation. The experienced a higher degree of living environment alienation, oppression and senselessness from the sub-dimension of adolescent alienation. The development trend of adolescents' alienation generally appeared in three stages: the first smooth change and then the "V" shape change, the last was a smooth change. (2)On the whole, the adolescents of minority nationalities in Han district experienced a moderate degree of the personality problem trend. They experienced a higher degree of negative emotion and a lower degree of health problems and suicidal tendencies. Adolescents' personality problem development tendencies was a typical "U" shaped change.(3)Peak period is first year of high school and trough period is college freshman both in the alienation or personality problems. (4)There was a significant correlation between alienation and personality tendency. The degree of alienation had a good predictive effect on personality problems tendency.
\end{abstract}

\section{Introduction}

Teenagers are in a special stage of rapid physical and mental change. The development of physiology is at an accelerated stage, and all aspects of the body develop rapidly, and the level of mental development is still in the transition from immature to mature. It is the maturity of the external representation of the body and the relative slow development of its inner psychology that cause the imbalance and mismatch between its physiological and psychological development and cause psychological development contradictions. From the existing literature, Sandhu \& Tung (2004) believes that teenagers at different stages of self identity have different feelings of alienation. Adolescents with high self identity had less experience of alienation, while adolescents in the period of delay and the same sexual confusion had more experience of alienation ${ }^{[1]}$. The main reason for adolescent behavior problems, criminal behavior is caused by the high sense of alienation (Slater, 2003; Cetinkanat $\&$ Kösterelioğlu, 2016) ${ }^{[2]-[3]}$. However, the empirical study shows that the study of alienation and personality problems is still an unexplored field. Especially in the context of multi-ethnic cultural integration and collision, it is of great practical significance and theoretical significance to combine alienation and personality problems.

The study used ethnic minority adolescents living in the Han District as an analysis object. On the one hand, they are in a special period of physical and mental development, On the other hand, they face the contradiction and friction between ethnic groups and Han culture, customs, beliefs(Liu \& Yang, 2005) ${ }^{[4]}$. Compared with the Han teenagers, they are more likely to experience a sense of high alienation and tend to be more prone to personality problems. 


\section{Research Methods}

Subjects. The study adopted the cluster random sampling method to randomly selected sample in Sichuan, Yunnan, Guizhou and other ethnic minorities. 586 valid questionnaires were obtained. The investigation involves the students of 30 ethnic groups, mainly Buyi, Tujia, Xinjiang Uygur and Miao. Demographics include grade, sex, region, the only child, and the length of sinization time. An overview of the survey samples is shown in the following table1.

Table 1 Survey of effective survey samples $(\mathrm{N}=586)$

\begin{tabular}{|c|c|c|c|c|c|c|c|}
\hline variable & classification & number & $\%$ & variable & classification & number & $\%$ \\
\hline \multirow[t]{2}{*}{ Gender } & Male & 302 & $51.54 \%$ & \multirow[t]{2}{*}{ One child } & Yes & 318 & $54.27 \%$ \\
\hline & Female & 284 & $48.46 \%$ & & No & 268 & $45.73 \%$ \\
\hline \multirow{3}{*}{$\begin{array}{l}\text { Grade } \\
\text { distribution }\end{array}$} & $\begin{array}{l}\text { First grade in high } \\
\text { school }\end{array}$ & 90 & $15.36 \%$ & \multirow{3}{*}{$\begin{array}{l}\text { Grade } \\
\text { distribution }\end{array}$} & Sophomore & 97 & $16.55 \%$ \\
\hline & Senior high school & 97 & $16.55 \%$ & & Junior & 99 & $16.89 \%$ \\
\hline & Freshman & 101 & $17.24 \%$ & & Senior & 102 & $17.10 \%$ \\
\hline \multirow{4}{*}{$\begin{array}{l}\text { Regional } \\
\text { distribution }\end{array}$} & Big city & 87 & $14.85 \%$ & \multirow{4}{*}{$\begin{array}{l}\text { sinization } \\
\text { time }\end{array}$} & Less than 3 years & 143 & $24.40 \%$ \\
\hline & Middle city & 180 & $30.72 \%$ & & 3-5year & 156 & $26.62 \%$ \\
\hline & Small city & 183 & $31.22 \%$ & & 5-10year & 175 & $29.86 \%$ \\
\hline & Villages and towns & 136 & $23.21 \%$ & & More than 10year & 112 & $19.11 \%$ \\
\hline
\end{tabular}

Research tools. The study adopted adolescent alienation scale developed by Yang Dong et al $(2002)^{[5]}$.The scale consists of 52 items, two levels and nine dimensions. The first level is object alienation, including alienation of family, alienation of friends, alienation of nature, alienation of living environment four dimensions. The second level is abstract, vague sense of alienation, including meaningless sense, no sense of control, normlessness, oppression and social isolation.

PAS personality scale was developed by the early PAI. The scale consists of 22 items and 10 dimensions, including negative emotion(NA), problem behavior(PB), health problem (HP), psychotic features(PF), social support(SW), himself control(HC), suicide(ST), distant (AN), alcohol problem(AP) and anger control (AC) ${ }^{[6]}$. The likert7 point scale scoring method was used to evaluate the total non conformity to the total coincidence of 1-7 points respectively.

\section{Results and Analysis}

Test of reliability and validity of research variables. SPSS was used to test the Cronbach's $\alpha$ reliability of scales, and AMOS was used to test the structural validity of the research variables. The results are shown in Table 2.

Table 2 Test of reliability and validity of measuring tools $(\mathrm{N}=586)$

\begin{tabular}{|c|c|c|c|c|c|c|c|c|c|}
\hline Mame of the scale & Alpha & $\chi^{2} / \mathrm{df}$ & RMSEA & AGFI & GFI & IFI & CFI & NFI & NNFI \\
& & & & & & & & & \\
\hline adolescent alienation & 0.93 & 1.89 & 0.05 & 0.97 & 0.98 & 0.98 & 0.98 & 0.98 & 0.98 \\
\hline Personality problem tendencies & 0.89 & 2.25 & 0.06 & 0.97 & 0.98 & 0.98 & 0.97 & 0.98 & 0.98 \\
\hline
\end{tabular}

The Cronbach's values were higher than 0.80 . The results of confirmatory factor analysis by $\chi^{2} / \mathrm{df}$ values were less than 5, RMSEA value was less than 0.8 , the rest of the index values are close to or in 0.90 , indicating good internal consistency reliability and structure validity.

The survey results of alienation. The average scores and standard deviations of alienation are calculated, as shown in Table 3. 
Table 3 the average scores and standard deviations of alienation( $\mathrm{N}=586)$

\begin{tabular}{|c|c|c|c|c|c|c|c|c|c|c|c|}
\hline \multicolumn{2}{|c|}{ Alienation } & $\begin{array}{c}\text { Meaning } \\
\text { lessness }\end{array}$ & $\begin{array}{c}\text { Self } \\
\text { alienation }\end{array}$ & $\begin{array}{c}\text { Alone } \\
\text { ness }\end{array}$ & $\begin{array}{c}\text { Natural } \\
\text { alienation }\end{array}$ & $\begin{array}{c}\text { Family } \\
\text { alienation }\end{array}$ & $\begin{array}{c}\text { Alienation of } \\
\text { environment }\end{array}$ & $\begin{array}{c}\text { Oppre } \\
\text { ssion }\end{array}$ & $\begin{array}{c}\text { Uncontro } \\
\text { llable }\end{array}$ & $\begin{array}{c}\text { Social } \\
\text { alienation }\end{array}$ & $\begin{array}{c}\text { The total } \\
\text { score }\end{array}$ \\
\hline Male & M & 4.11 & 3.27 & 3.66 & 3.52 & 3.30 & 4.76 & 4.43 & 4.04 & 3.46 & 3.84 \\
\hline & SD & 1.20 & 1.20 & 1.22 & 1.38 & 1.31 & 1.23 & 1.14 & 1.22 & 1.29 & 0.90 \\
\hline Female & M & 3.97 & 3.04 & 3.56 & 3.15 & 2.74 & 4.54 & 4.16 & 3.90 & 3.02 & 3.56 \\
\hline & SD & 1.22 & 1.10 & 1.14 & 1.17 & 1.23 & 1.37 & 1.31 & 1.17 & 1.25 & 0.86 \\
\hline Total & M & 4.04 & 3.16 & 3.61 & 3.34 & 3.04 & 4.66 & 4.31 & 3.98 & 3.25 & 3.71 \\
\hline & SD & 1.21 & 1.16 & 1.18 & 1.30 & 1.30 & 1.30 & 1.23 & 1.20 & 1.29 & 0.89 \\
\hline
\end{tabular}

On the whole, Han minority adolescents experience a moderate degree of alienation, and the overall alienation is $M=3.71$, and male alienation degree $(M=3.84)$ is slightly higher than that of female $(M=3.56)$. From the dimensions of alienation, both male and female adolescents, the highest score and more than the midpoint (scale is based on the Likert 7 points) is the living environment of alienation, oppression and meaninglessness. The alienation of young students is mainly reflected in the above three aspects.

Investigation results of personality problems trend. The average scores and standard deviations of all items in all dimensions of personality problems trend are calculated, and the results are shown in Table 4.

Table 4 the average scores and standard deviations of personality problems $(\mathrm{N}=586)$

\begin{tabular}{|c|c|c|c|c|c|c|c|c|c|c|c|c|}
\hline $\begin{array}{c}\text { personality problems } \\
\text { Gender }\end{array}$ & NA & PB & PF & HP & SW & HC & ST & AN & AC & AP & $\begin{array}{c}\text { PAS } \\
\text { Total }\end{array}$ \\
\hline Male & M & 4.67 & 2.37 & 2.36 & 2.04 & 2.38 & 3.17 & 1.39 & 2.42 & 2.19 & 2.38 & 25.32 \\
\hline & SD & 1.81 & 1.53 & 1.54 & 1.36 & 1.48 & 1.31 & 1.82 & 1.33 & 1.38 & 1.42 & 7.83 \\
\hline Female & M & 4.55 & 1.82 & 1.79 & 1.81 & 2.55 & 2.74 & 1.50 & 2.34 & 1.98 & 1.68 & 22.40 \\
\hline & SD & 2.16 & 1.77 & 1.78 & 1.50 & 1.39 & 1.12 & 1.90 & 1.24 & 1.47 & 1.77 & 8.71 \\
\hline Total & M & 4.61 & 2.11 & 2.10 & 1.94 & 2.46 & 2.97 & 1.44 & 2.39 & 2.09 & 2.05 & 23.99 \\
\hline & SD & 1.98 & 1.67 & 1.67 & 1.43 & 1.44 & 1.24 & 1.86 & 1.29 & 1.42 & 1.63 & 8.35 \\
\hline
\end{tabular}

American personality assessment center model showed that the total score of 19-23 is the middle level of personality problem, and 24-44 was a significant personality problem. The results of the survey showed that students had a moderate to significant degree of personality problems. From the perspective of gender, the scores of personality problems and their scores in all dimensions of male adolescents are higher than those of female. Male students have more serious personality problems than female students. From the various dimensions of personality problems, The above the median value 4 points are mainly concentrated in negative emotions, with fewer health problems and suicidal tendencies.

The trend of the development and change of teenage alienation in grade. From the perspective of development, the situation of the alienation of the minority nationalities in the Western Han Dynasty is investigated. See Figure 1:

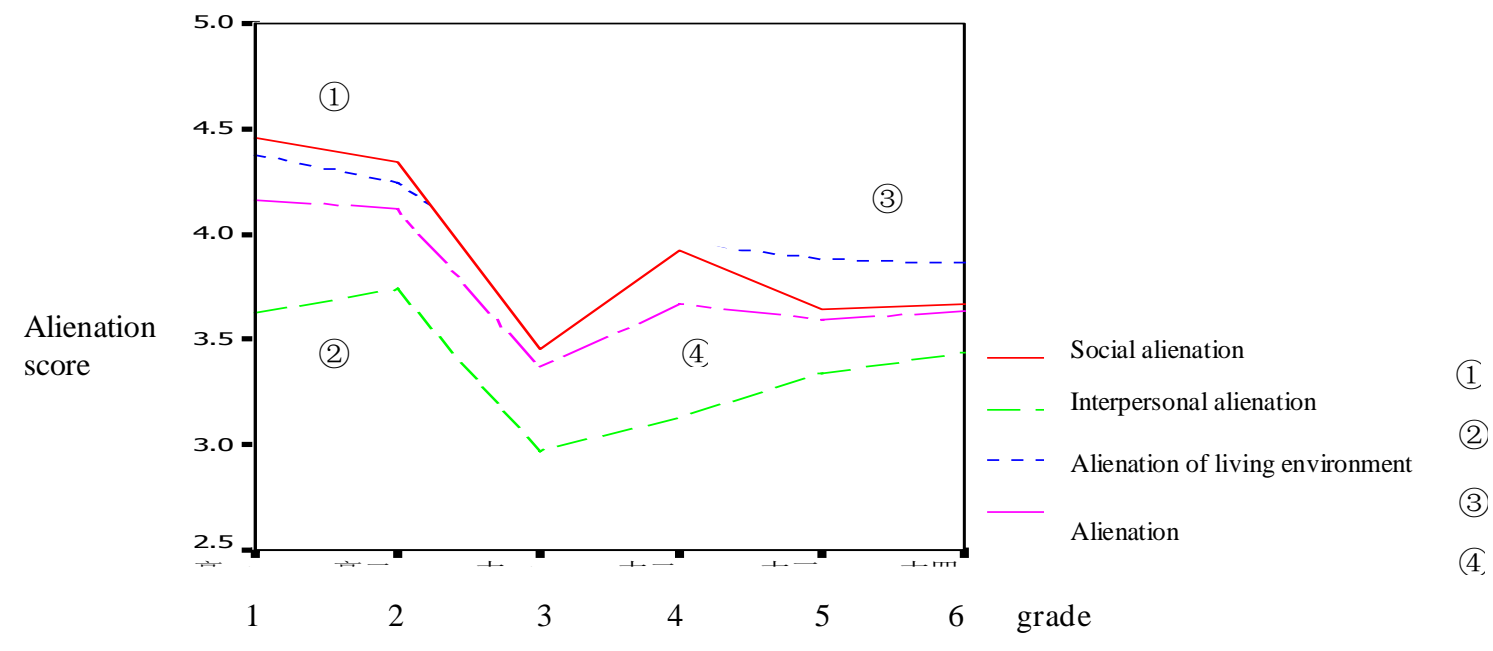

Figure1 The trend of alienation of minority nationalities teenage 
From Figure 1, we can see that the alienation, social alienation, interpersonal alienation and alienation of living environment are the same trend of development and change. In general, first grade in high school experience the strongest alienation, and the freshmen experience the least alienation. Specifically, it can be further divided into 3 stages. The change of various types of alienation is small and peaceful in the first stage that is from the high level to the second grade, but this stage is the peak of the sense of alienation. The second stage is from sophomore to sophomore. All kinds of alienation perceived by adolescents experience a " $\mathrm{V}$ " change. The experience of alienation among freshmen is the lowest, and the experience of alienation is significantly reduced compared with high school students. The degree of alienation is smaller and slower in the third stage that is from the sophomore to the senior period. The degree of alienation experience has an upward trend compared with the previous stage.

The development and change of personality problem in grade. From the perspective of development, the development and changes of the personality problems of ethnic minority adolescents in the Han Dynasty are analyzed, and the results are shown below.

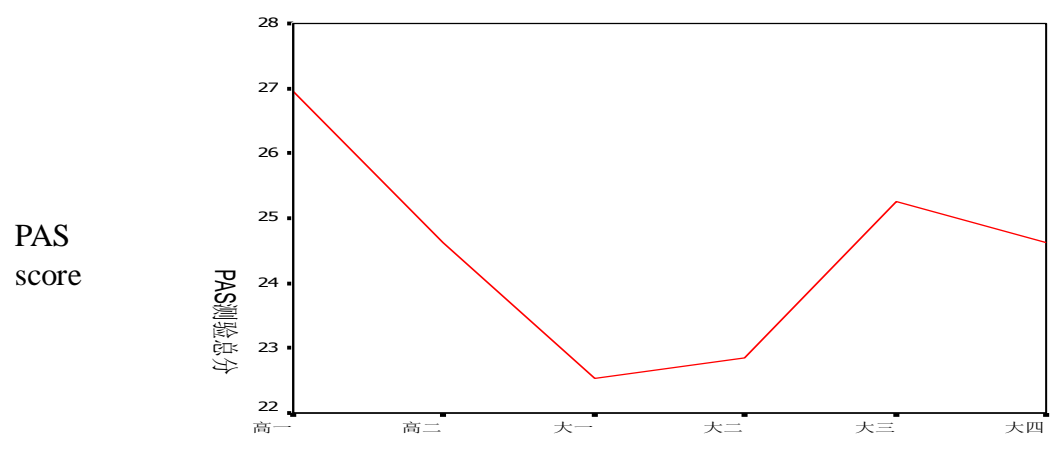

Figure2 I ne trend of personality problems of minority nationalities teenage

From Figure 2, we can see that the probability of personality problems is the highest when they are first grade in high school, and the probability of appearing in the freshmen and sophomores is relatively small. After that, personality problems tend to rise. There is a " $U$ " change trend in grade variables.

The relationship between adolescent alienation and personality problems. The correlation between adolescent alienation and personality problems was analyzed by Pearson correlation. The results were shown in the table below.

Table 5 correlation coefficient between alienation and personality problem $(\mathrm{N}=586)$

\begin{tabular}{|c|c|c|c|c|c|c|c|c|c|c|}
\hline $\begin{array}{l}\text { Alienation } \\
\text { Personality }\end{array}$ & $\begin{array}{l}\text { Meaningl } \\
\text { essness }\end{array}$ & $\begin{array}{l}\text { Self } \\
\text { alienation }\end{array}$ & $\begin{array}{c}\text { Alone } \\
\text { ness }\end{array}$ & $\begin{array}{l}\text { Natural } \\
\text { alienation }\end{array}$ & $\begin{array}{l}\text { Family } \\
\text { alienation }\end{array}$ & $\begin{array}{l}\text { Environment } \\
\text { alienation }\end{array}$ & $\begin{array}{l}\text { Oppre } \\
\text { ssion }\end{array}$ & $\begin{array}{l}\text { Uncontr } \\
\text { ollable }\end{array}$ & $\begin{array}{c}\text { Social } \\
\text { alienation }\end{array}$ & $\begin{array}{l}\text { Total } \\
\text { score }\end{array}$ \\
\hline NA & $0.39 * *$ & $0.37 * *$ & $0.45 * *$ & $0.23 * *$ & $0.23 * *$ & $0.20 * *$ & $0.30 * *$ & $0.36 * *$ & $0.37 * *$ & $0.45 * *$ \\
\hline $\mathrm{PB}$ & $0.16^{* *}$ & $0.30 * *$ & $0.24 * *$ & $0.13^{*}$ & $0.27 * *$ & $0.23 * *$ & $0.17 * *$ & $0.19 * *$ & $0.27 * *$ & $0.29 * *$ \\
\hline $\mathrm{PF}$ & $0.16^{* *}$ & $0.30 * *$ & $0.24 * *$ & $0.13^{*}$ & $0.27 * *$ & $0.23 * *$ & $0.17 * *$ & $0.19 * *$ & $0.27 * *$ & $0.29 * *$ \\
\hline $\mathrm{HP}$ & $0.27 * *$ & $0.27 * *$ & $0.26 * *$ & $0.21 * *$ & $0.31 * *$ & $0.12 *$ & $0.25 * *$ & $0.24 * *$ & $0.20 * *$ & $0.33 * *$ \\
\hline SW & $0.15^{*}$ & $0.35^{* * *}$ & $0.36^{* *}$ & 0.03 & 0.10 & 0.07 & 0.09 & $0.19 * *$ & $0.19 * *$ & $0.25 * *$ \\
\hline $\mathrm{HC}$ & 0.08 & 0.03 & 0.10 & $0.25 * *$ & $0.16^{* * *}$ & $0.17 * *$ & $0.15^{*}$ & 0.03 & $0.29 * *$ & $0.17 * *$ \\
\hline ST & $0.35 * *$ & $0.31 * *$ & $0.35 * *$ & $0.27 * *$ & $0.35^{* * *}$ & $0.19^{* *}$ & $0.27 * *$ & $0.34 * *$ & $0.37 * *$ & $0.48^{* *}$ \\
\hline AN & 0.09 & $0.24 * *$ & $0.33 * *$ & $0.17 *$ & 0.08 & 0.10 & $0.12 *$ & $0.18^{* *}$ & $0.20 * *$ & $0.23 * *$ \\
\hline $\mathrm{AC}$ & $0.27 * *$ & $0.29 * *$ & $0.22 * *$ & $0.18 * *$ & $0.31 * *$ & 0.07 & $0.14^{*}$ & $0.24 * *$ & $0.29 * *$ & $0.29 * *$ \\
\hline $\mathrm{AP}$ & 0.06 & $0.23 * *$ & $0.15^{*}$ & 0.05 & $0.20 * *$ & 0.11 & 0.05 & 0.09 & $0.20 * *$ & $0.17 * *$ \\
\hline Total PAS score & $0.38 * *$ & $0.50 * *$ & $0.52 * *$ & $0.31 * *$ & $0.44^{* *} *$ & $0.29 * *$ & $0.33 * *$ & $0.40 * *$ & $0.51 * *$ & $0.57 * *$ \\
\hline
\end{tabular}

The moderate to high degree of correlation between the total score of alienation and the total score of PAS $(\mathrm{r}=0.57 * *)$ was found in the above table. From the perspective of dimension, the correlation coefficients of social withdrawal and natural environment alienation, family alienation, alienation of living environment and oppression, self alienation and loneliness, uncontrolled anger control and life alienation; alcohol dependence and living environment alienation, oppression, sense of control are not significant. Besides, there is a significant positive correlation between the different dimensions of alienation and other personality problem tendency. 


\section{Discussion}

The current situation and development law of alienation. The reason why high school students experience high alienation is that: (1) High school students are characterized by paying more attention to their personality and more rich of psychological activity also the less of explicit behavior in the psychological weaning period. Their self consciousness is more often and deeper to their inner world, and their heart will gradually closed, in addition they are lack of trust and satisfaction to the outside. Therefore, high school students often feel very lonely. (2) The pressure of study is high, mainly including the school's overemphasis on examination results, family elders' wang feng-f mentality, unrealistic expectations of children, and abnormal competition in examination oriented Education in high school. All these pressures put high school students on a heavy load of thought. They are in a state of tension and anxiety for a long time, which leads them to have no time to maintain intimate contact with natural environment and interpersonal relationships. The above reasons may cause high school students to be self closed, emotional indifference, and an increase in alienation.

There are two obvious inflexion points for the alienation of the minority teenager students in the Han District of the University. The steady decline of alienation in the first and the second grade of the University period was mainly due to the following: (1)Through high school in the relatively heavy school period, the life and academic pressure dropped abruptly. Freshman and sophomore have plenty of time to do what they like, and to autonomously learn that changed from forced pressure. College students get a higher sense of achievement and freedom, which reduces the sense of constraint and constraint from family and society, due to the expansion of knowledge, the increase of interpersonal interaction and the improvement of eye pattern. (2) The increasing of alienation of junior and senior are mainly from all kinds of increasing pressures, including more complex interpersonal relationships, intense employment pressure, competition for postgraduate studies. Therefore, the junior and senior students are full of worries, anxieties about the future that is full of confusion and bewilder.

The current situation and development law of personality problems. The high school stage and the high grade of the university are the time of the personality tendencies more prominent, which deserves the attention of all walks of life. The reasons for the serious problem of personality tendency in high school stage are: Many high school students start from high school to the Han District to study, and have to face the internal conflict between the ethnic culture and the Han culture. High school students are baptized by their own cultural heritage, religious beliefs, values and so on, and penetrated into their behavior habits, social life and so on when they live in the minority areas for a long time. Later, because of school and other reasons, they had to live in the Han residence area. Influenced by the Han culture, young students are likely to face two kinds of conflicts and collisions between different cultures, resulting in psychological discomfort.

In addition, the pressure of college senior students is suddenly increasing. The college senior students need to redefine and think about the real value of knowledge, how to integrate into the society, how to get friends and love, how to experience the joy and meaning of life and so on during period of transition from Pyramid to society. If these questions are not well answered, they cannot be well adapted to the changes in the environment. The defects of potential personality, such as strong self-consciousness, excessive anxiety and depression, are becoming more and more prominent with the change of the environment.

The comparative analysis of alienation and personality problems. The results of $T$ test showed that the group with a high degree of alienation showed more negative emotions, problem behaviors, mental traits, health problems, social withdrawal, self control, suicide attempts, alienation, anger control, alcohol dependence and other personality problems. This is very consistent with the study of Tang Yihui (2004), that is, the high alienation is characterized by emotional excitement, lack of confidence, anxiety and depression and so on ${ }^{[7]}$. Alienation is a negative feeling in the heart, and personality problems tendency is an external 
behavior that may be triggered. Meanwhile, there is a significant positive correlation between the total scores of alienation and personality problems, which indicates that alienation can predict the occurrence of personality problems to a certain extent.

\section{Relevant Recommendations}

Young people are sensitive and feel rich, and it is difficult to get effective social support because of shyness. Therefore, both family members and teachers should take the initiative to communicate with them, try to understand thinking of young students. The strong social support system should be established to reduce helplessness and loneliness.

The young students should be clearly aware of their cognitive and emotional state, realize the harm of negative emotions on their physical and mental health, take the initiative to seek ways to talk or get help, adopt self education, self discipline, self suggestion, diversion and other methods to regulate negative emotions.

School should develop students' good interpersonal relationships, encourage students to integrate into collectives, and learn to respect social conventions, care for others' needs, sincere compliments, focus on communication, maintain self-esteem and independence.

\section{Acknowledgments}

This research was funded by the National Natural Science Foundation Project: (71663060); Humanities and Social Sciences Program of the Ministry of Education (15YJC630039).

\section{Reference}

[1] Sandhu, D.,\& Tung, S. Contributions of Family Environment and Identity Formation towards Adolescents'Alienation[J]. Pakistan Journal of Psychological Research, 2004, 19(1): 1-14.

[2] Slater, M. D. Alienation, aggression, and sensation seeking as predictors of adolescent use of violent film, computer, and website content[J]. Journal of Communication. 2003, 53(1):105-121.

[3] Cetinkanat, A. C. \& Kösterelioğlu, M. A. Relationship between Quality of Work Life and Work Alienation: Research on Teachers[J]. Universal Journal of Educational Research, 2016, 4(8): 1778-1786,

[4] Liu Xi, Liu Xi, Yang Dong. Sense of cultural alienation on minority students living in Han District - the theoretical hypothesis and questionnaire designing[J]. Chinese Journal of clinical psychology, 2005,13 (2): 141-146.

[5] Yang Dong, Zhang Jinfu, Huang Xiting. Adolescent students' sense of alienation: The theoretical construction and scale development[J]. Acta Psychology Sinica, 2002, 34(4): 407-413.

[6] Morey, L. C. PAI interpretive explorer module manual[M]. Odessa, FL: Psychological Assessment Resources. 1999.

[7] Tang Yi-hui, Huang Hai \& Lei Liang-Xin. Relationship among the family functioning and personality and alienation of adolescents[J]. Chinese Journal of Clinical Psychology, 2004,12(2): 158-160. 